\title{
Generating Essentials for Childhood: New Roles in Child Protection for the U.S. Federal Government and the Public Health Sector
}

\author{
Jill D. McLeigh ${ }^{1,2} \cdot$ Gary B. Melton ${ }^{2}$
}

Published online: 18 February 2019

(C) Springer Nature Switzerland AG 2019

This article offers a commentary on Essentials for Childhood, a Centers for Disease Control and Prevention (CDC) initiative that is the focus of this special issue. The Essentials for Childhood framework seeks to promote positive development of children and families by promoting policies, programs, and norms that ensure children and their caregivers experience safe, stable, and nurturing relationships and environments. According to the theory undergirding the framework, children and caregivers can better cope with the effects of potential stressors that could lead to child maltreatment when these relationships and environments are present (CDC 2013).

In focusing on prevention and in recognizing the need for a large-scale, multilevel, and cross-sector approach, CDC's framework represents a shift in the way the government thinks about and supports child protection. Indeed, the foundation of this public health approach to addressing child maltreatment in CDC gives it special weight. A leader of the initiative (also the editor of this issue), Joanne Klevens, and her colleagues deserve recognition not only for their courage in launching Essentials for Childhood, but also for making a careful attempt to document their efforts and evaluate their results.

To provide context regarding this shift toward a public health approach to child maltreatment and how CDC has implemented Essentials for Childhood, this commentary considers how the field has developed, how and why past efforts have been misdirected, and how efforts can be placed on course. In addition to recognizing the merits of CDC's leadership in the effort, it describes how the scope and the impact of the initial work may have been limited by their auspice in CDC. The commentary concludes with recommendations for next steps for Essentials for Childhood and more broadly for the field.

Jill D. McLeigh

jill.mcleigh@childrens.com

1 Rees-Jones Center for Foster Care Excellence, Children's Health, Dallas, TX 75235, USA

2 The Kempe Center, University of Colorado Anschutz Medical Campus, Aurora, CO, USA 


\section{Background}

In "The Battered Child Syndrome," physician C. Henry Kempe and his colleagues (Kempe et al. 1962) suggested that a few hundred cases of parent-inflicted child maltreatment occurred annually in the United States. Soon after the article was published, the Children's Bureau convened meetings with the goal of discerning how it could best help states take action on child abuse (Myers 2008). At one of the meetings, Kempe recommended state legislation that would require physicians to report suspected abuse to police or child welfare (Myers 2008). By 1967, all 50 states had mandatory reporting laws.

Kempe's research and advocacy, and the subsequent policy response, played a significant role in increasing awareness of child maltreatment, especially physical and sexual abuse. Advances in data collection and research since that time, however, have shown that that the scale and scope of child maltreatment are much greater than originally thought. Definitions of what constitutes child maltreatment have expanded, as have the number of reports and substantiated cases. ${ }^{1}$

Further, our understanding of the epidemiology of child maltreatment has increased in the years since the development of our current child welfare system. We now know that maltreatment results from a complex array of stressors, such as poverty and material hardship (e.g., Cancian et al. 2013; Maguire-Jack and Font 2017; Pelton 2015; Slack et al. 2017; Warren and Font 2015; Yang 2015; Yang and Maguire-Jack 2016), neighborhood disadvantage (Coulton et al. 2018; Drake and Pandey 1996; Freisthler 2004; Maguire-Jack and Font 2017; McLeigh et al. 2018), lack of social support (e.g., Freisthler et al. 2014; Thompson 1995, 2015; Turner and Avison 1985) and community cohesion (e.g., Barnhart and Maguire-Jack 2016; Emery et al. 2015; Garbarino and Kostelny 1992; Kim and Maguire-Jack 2015; Maguire-Jack and Showalter 2016; Maguire-Jack and Wang 2016; Molnar et al. 2016; Weissbourd and Grimm 1981; Zolotor and Runyan 2006), the built environment (Haas et al. 2018; McDonell and Skosireva 2009) and changing family dynamics (e.g., Melton et al. 2002). Indeed, mounting research evidence from as early as the 1980s has suggested that comprehensive child maltreatment prevention efforts need to address communitylevel structures and processes (e.g., Barry 1994; Belsky 1980; Garbarino and Kostelny 1992; Garbarino and Sherman 1980; Melton 1992; National Commission on Children 1991; Schorr 1988).

The U.S. Advisory Board on Child Abuse and Neglect (1990) clearly articulated this message when it proclaimed that child maltreatment had escalated to the level of a national emergency, based on the number of reports and its negative consequences. The U.S. Advisory Board expressed regret over the billions of dollars that had been spent on

\footnotetext{
${ }^{1}$ Although the number of cases of physical and sexual abuse has been declining (Finkelhor et al. 2015), the scope of the problem remains enormous. In 2016 in the United States, 4.1 million referrals were made to child protection authorities because of suspected child maltreatment of 7.4 children (U.S. Department of Health and Human Services 2018). Of the 3.5 million children who received either an investigation or an alternative response (the remainder of the reported children were screened out without any response), 676,000 children were found by child protection authorities to have been subjected to child abuse or neglect. A reflection of the continued weakness in the system is that state and county child protection authorities acknowledged that more than two-fifths of the children known to have been maltreated received no post-response services (U.S. Department of Health and Human Services 2018). In effect, the only "service" was an investigation, even for these children with officially substantiated cases of child maltreatment.
} 
a system that failed to protect children and called for a new national child protection strategy. In a subsequent report, the U.S. Advisory Board (1993) concluded, "The most serious shortcoming of the nation's system of intervention on behalf of children is that it is reactive and investigatory in nature instead of proactive and preventative ..." (p. ix).

In calling for a community-based approach to child maltreatment prevention, the U.S. Advisory Board (1993) focused on the need to change community environments (in effect, to take a universal approach). To reduce maltreatment and increase child well-being, the report called for the creation of caring communities built on an ethic of mutual support. The proposed strategy reframed child protection so that, rather than focusing upon the criteria for coercive intervention in individual families, the principal question was how government could facilitate community action to prevent or ameliorate harm to children.

The research base supporting the U.S. Advisory Board's recommendations has continued to grow. From 2002 to 2008, a large-scale effort to carry out the proposed strategy was launched in a portion of metropolitan Greenville, SC (Kimbrough-Melton and Melton 2015). Results from the evaluation of that initiative found significant increases in variables measuring positive neighborhood-level processes (e.g., social support; collective efficacy), improvements in perceptions of children's safety in the home and positive parenting practices, and declines in rates of child maltreatment substantiated by child protection authorities, hospital records of ICD-9 coded child injuries suggesting child maltreatment, and danger at school and en route to and from school, as perceived by teachers, parents, and schoolchildren (McDonell et al. 2015).

In 2013, several of the scholars and practitioners whose research and insights were critical to the development of the U.S. Advisory Board's recommendations convened at The Kempe Center at the University of Colorado Anschutz Medical Campus to reflect on developments in the field during the 20 years that had passed since the Board released its proposed national strategy. The general conclusion from this meeting was that not only do the report's conclusions still stand, but that there is now more evidence supporting the recommendations (McLeigh and Melton 2015; Nadan et al. 2015; Pelton 2015; Thompson 2015).

\section{Prevailing Understandings of Child Maltreatment}

Despite the U.S. Advisory Board's recommendations and the growing body of supportive research, child maltreatment continues to be viewed as an individual problem (i.e., bad parents doing bad things to their children). Indeed, the FrameWorks Institute (2004) conducted interviews and focus groups, along with a review of existing surveys and reports, and found that the public viewed child maltreatment as something that "bad" or "selfish" parents do.

This view of child maltreatment as a "parent problem" is also seen in the policy advanced to address child maltreatment. Even as the federal government moves toward support for prevention initiatives, such initiatives have continued to focus on the parent (especially mothers; e.g., home visitation, family support services, substance use treatment programs, domestic violence services). For example, the Family First Prevention Services Act of 2017 calls for the provision of mental health and substance abuse prevention and treatment services, in-home parent skill-based programs, and 
kinship navigator services. Indeed, prevention efforts continue to view child maltreatment as a result of parental ineptitude or moral deficit instead of focusing on the role of the complicated and powerful social, economic, and cultural factors at play.

\section{Efforts to Prevent Child Maltreatment}

Although federal programs and policies intended to prevent child maltreatment have generally lacked a focus on these factors, some foundations have experimented with funding innovative initiatives that have sought to address the complicated array of factors influencing caregivers' ability to keep their children safe. For example, beginning in 2002, The Duke Endowment provided multi-year grants to two initiatives that sought to provide community-level child maltreatment prevention. The Strong Communities initiative, described in detail in Kimbrough-Melton and Melton (2015), focused on enhancing support for families with young children by strengthening neighbor-to-neighbor assistance. The initiative sought to ensure that every child and every parent would know that they had support available in the settings of everyday life (e.g., school, workplaces, child-care centers, places of worship). The second initiative, the Durham Family Initiative (Dodge et al. 2004), sought to strengthen and expand availability of community-based, evidence-based direct services to families using a prevention system of care model. Another foundation, the Doris Duke Charitable Foundation, has shifted from an emphasis on parent education to a place-based approach that stresses the role of communities in promoting child well-being and preventing child maltreatment (Bassett 2013).

These examples represent the exception, not the rule. Most primary prevention efforts in the field of child maltreatment have tended to focus on awareness raising and individual-level interventions. These efforts have not been without some success; physical and sexual abuse rates in the United States have remained well below those of the early 1990s (Child Trends 2018). These declines are probably also attributable, however, to larger societal trends in the way that people treat one another. The rights of racial minorities, women, people with disabilities, and sexual minorities have all improved since the early 1990s (although there is still work to do!). Thus, it is not surprising to see improvements in the way that children are treated.

These advances, however, have focused on things people should not do (e.g., never hit a child; do not use racial slurs). Preventive efforts often have emphasized halting bad things from happening instead of promoting positive outcomes for children. Based on their findings from two experimental surveys, the FrameWorks Institute (2009) recommended devoting more effort to explaining how child development works, identifying practices - both societal and interpersonal-that promote healthy development, and focusing public attention on community resources to assist children and families.

\section{Essentials for Childhood}

It is against this backdrop that CDC launched the public health initiative entitled Essentials for Childhood, so named to adhere to the recommendations of the 
FrameWorks Initiative, "to shift the narrative from a deficit-based conversation to a positive one that focused on providing ALL children what they need to thrive" (Klevens and Alexander, this issue). The federal initiative seeks to create safe, stable, nurturing relationships and environments for all children by (a) raising awareness and commitment, (b) using data to inform actions, (c) creating the context for healthy children and families through norms change and programs, and (d) creating the context for healthy children and families through policies (Klevens and Alexander, this issue). As described in the articles included in this issue, to implement the initiative CDC issued grants to five state public health departments that were required to partner with Prevent Child Abuse America, National Alliance for Children's Trust and Prevention Funds, or Parents Anonymous to build their capacity to prevent child maltreatment. Organizations receiving grants were further required to utilize a collective impact approach, which requires "the commitment of a group of important actors from different sectors to a common agenda for solving a specific social problem at scale" (Kania and Kramer 2011, p. 36) and includes five conditions that differentiate it from other models of collaboration: common agenda, shared measurement, mutually reinforcing activities, continuous communication, and backbone support.

The articles in this special issue provide insights from the first 5 years of the initiative. The first article, written by Klevens and CDC consultant Sandra Alexander, describes the process undertaken by CDC that led to the adoption of their approach to change in the field of prevention of child maltreatment. The next four articles provide an overview of how the effort unfolded in each of four states (California, Colorado, North Carolina, and Kansas). Each of these articles supplies background information on the infrastructure and efforts to date to address child maltreatment in their respective states. The articles then report findings, with a focus on the core elements of a collective impact approach and a summary of accomplishments and challenges. A cross-state analysis by Wasilewski et al. synthesizes these findings.

The authors highlight the importance of having a common agenda and the relative ease with which it was established. There also seemed to be consensus around the structure, with a steering committee setting the mission and vision, followed by the recruitment of additional participating organizations and the formation of workgroups to figure out how to meet the established goals. Three of the four of projects had public health departments as the lead or co-lead organization. (The exception was North Carolina, where the lead organization was the Prevent Child Abuse affiliate for 3 years, followed by the state's Institute of Medicine for 2 years.)

Accomplishments varied across states. Two states added modules on adverse childhood experiences to existing data collection tools. Most of the evaluators concluded that the backbone organizations had embraced and incorporated the goals, principles, and public health perspective into their broader organizational structure. Other accomplishments included an increase in family-friendly employment practices and new and strengthened partnerships across agencies and organizations.

Across sites, several challenges were identified. These challenges included a lack of clarity among stakeholders about the process, a lack of urgency in the collective impact process, problems of access to support from high-level leadership, difficulty in changing policy when the lead entity is a state agency, and inadequacy of funding and staff. Some participants also reported difficulty in maintaining communication channels and clarity of message (i.e., the goal was difficult to understand). 


\section{The Significance of Essentials for Childhood in Historical Context}

No matter how noble that the intentions of legislators and administrators have been over the years, government action to protect children has been a checkered processcommonly inadequate in scope, misdirected in goals, and slow to reform. Initiated in the late 19th and early 20th centuries, the first such efforts to "save" children were led by Societies for the Prevention of Cruelty to Children, an awkwardly titled set of organizations (the name having been derived from charities for protection of animals) that became colloquially known as "The Cruelty" (Levine and Levine 1992). (For an illuminating account of the parallels between the early child-saving movements in the United States and Scandinavia, see Dahl 1985.) Such organizations commonly obtained substantial legal authority, in effect as arms of law enforcement. Although they did rescue some children from horrific situations of physical abuse and child labor, they often punished parents and institutionalized their children because of revulsion engendered by cultural practices of new immigrants:

The child savers...were horrified by the immigrants' use of garlic in cooking and their habit of drinking wine with dinner, and they decided that these were adequate bases for removing children. Appalled by what they perceived as the deviant lifestyles of immigrant families, the child savers sought to "improve" these families by insisting that children be quiet and clean, dress well, and eat "good" food, not traditional immigrant cuisine. (Huntington 2014, p. 75)

Early in the twentieth century and continuing through the New Deal, the child-saving movement did achieve the basics of federal attention to maltreatment of children, with periodic White House Conferences on Children and the establishment of the Children's Bureau. The federal role was primarily one of bully pulpit—not regulation. Indeed the first federal child labor legislation (the pertinent sections of the Fair Labor Standards Act) was not enacted until 1938, long after most of the states had begun to regulate or prohibit child labor.

Analogously, the federal role in child protection per se (i.e., the prevention and treatment of child abuse and neglect) did not arise until generations later (after Kempe's "discovery" of battered child syndrome). The first federal legislation (the Child Abuse Prevention and Treatment Act of 1974) came approximately a decade after the states adopted mandated reporting laws. Nonetheless, the initial federal string on CAPTA funding was simply the enactment of laws requiring reporting and investigation of suspected child maltreatment.

Moreover, as Nelson (1984) summarized in her seminal volume on the politics of child protection, CAPTA was ultimately enacted and then periodically re-authorized without serious reform through "the public use of private deviance" (p. 126). Both state and family policies emerged from Kempe's publication and systematic public presentation of some horrific cases, action that led to related media exposés of extreme physical abuse and, beginning a decade or two later, sexual abuse (see, e.g., Kempe 1978). Media attention to apparently sick or evil parents formed the basis for a "them" and "us" orientation that led to a continuing focus on finding those egregious cases, giving minimal attention to neglect (in policy but not in frequency of state intervention), and virtually ignoring social and economic factors that impede parents' care of 
children. In the enactment of CAPTA itself, Congress followed such an approach by highlighting the confessions of Jolly K. (the co-founder of Parents Anonymous) in the influential Senate hearings chaired by Walter Mondale.

Nelson (1984) has characterized child maltreatment as a valence issue (i.e., a policy problem that appears uncontroversial) and therefore undiscussable. After all, no one wants to be identified as an advocate for child abuse! Such an approach results, however, in avoidance of the nuances in policy (which, like the need to strengthen community support for families, may be quite profound), inattention to basic controversies, and influence of popular, even comfortable misconceptions.

Nelson's (1984) summary was apt:

Initially the problem [of child maltreatment] was constructed as parenting gone crazy, the awful violence that individual adults inflicted on individual children. This construction gave the issue support from conservatives as well as liberals. Indeed, when abuse first achieved governmental agendas, all but the most orthodox conservatives felt that the government's fiduciary role toward children included protecting them from physical violence. Policymakers were very wary, though, of associating abuse with physical discipline. They did not want to appear to be undermining the "natural authority" of parents over their children and were careful not to construct the problem as one of unequal power within the family. (p. 127)

Parton (2014) has made similar observations about modern child protection policy in wealthy democracies, with emphasis on England but attention to other countries in northern Europe, North America, and Oceania. Describing the "politics of outrage" [reform efforts derived from particular cases of egregious violence against children (Parton 2014, p. 11); see also Parton 1985, 1991, 2006, on the relation of child protection policy to social change], Parton (2014) has maintained that "debates about child protection systems...[are] not at their root technical but... [instead are] clearly political and concerned with different views about what constitute[s] the good society and, in particular, what the relationship should be... [among] the family, the child, and the state, and what the responsibilities of professionals should be in those arrangements" (p. 3).

"Ironically," Parton (2014) has added, "while child protection has become increasingly politicized, rarely has this led to any serious discussion of what we mean by child maltreatment and what are the best ways of trying to do something about it. These are major issues that have rarely received serious political attention and debate" (p. 11).

Critiquing conventional approaches to child welfare practice and policy, Gelles (2017) has pointed out that child protection reform (often after publicity about a particularly egregious case or even a media exposé of widespread failures across the specialty child welfare system) typically focuses on seemingly obvious "solutions" that relate to guild expectations and that answer media concerns about ineffective workers. The problem is that these "usual suspects" (Gelles's term) for child protection reform (e.g., more money; more staff; more training; a new agency head; a blue-ribbon panel; a new agency name) rarely would have been plausible strategies for prevention of the tragedies that stimulated the reform. Gelles's (2017, p. 77) central point is that the child protection system is so preoccupied with enforcing and 
enhancing the prerogatives of social workers and the agencies that employ them that it loses sight of the system's raison d'être (i.e., promoting "the safety and well-being of the child," who is "the most important client in the child welfare system") and accordingly fails to generate and apply a child-centered knowledge base with compatible structures and processes for keeping children safe. ${ }^{2}$

Indeed, Gelles (2017, p. 1) began his treatise by quoting the (U.S.) National Commission on Children's (1991) succinct condemnation of American child welfare practice:

If the nation had deliberately designed a system that would frustrate the professionals who staff it, anger the public who finance it, and abandon the children who depend on it, it could not have done a better job than the present child welfare system. (p. 293)

Put into this context, Essentials for Childhood is a groundbreaking initiative that has demonstrated some forward-looking federal and state government authorities' sensitivity to (a) scientific knowledge about the factors affecting the prevalence of child maltreatment and (b) social awareness of the potential effectiveness of diverse sectors of society (especially public health) in preventing maltreatment and mitigating its effects. It is stunning that such an approach is appropriately described as innovative. Logic would dictate its usefulness and indeed its expectable status, when one takes into account (a) the fundamental ethical and legal significance of preservation of children's personal security, (b) the corollary need for diligence in the design and implementation of means of fulfilling this communal duty through assistance to parents and other caregivers, and (c) the common sense and empirical evidence showing the importance of engaging the various settings of childhood in ensuring children's safety and well-being. Given, however, (a) the longstanding narrowness of conception of the goals and nature of child protection, (b) the traditional weight of politics over morals and science in child protection policy, and (c) the corollary slow pace and modest scale of reform, Klevens, the pertinent senior administrators of CDC, and the state grantees are to be commended for their

\footnotetext{
${ }^{2}$ The U.S. Advisory Board (1993) presaged Gelles's critique in its argument that a national child protection strategy should be child-centered. We agree that a strong normative foundation is critical in designing an effective child protection system. However, we also concur with the U.S. Advisory Board (see also Melton and Barry 1994; Melton et al. 2002) that such a system should be neighborhood-based. In that regard, we do not believe that Gelles (2017) goes far enough in drawing the desired boundaries of the child protection system. The specialty child welfare system is not broad enough to ensure children's safety in everyday life. On the other hand, Essentials for Childhood needs more attention to the normative foundation, although it takes beginning steps toward a broader child protection system.

We believe that Parton (2014) struck the correct balance:
}

...A broad public health approach to child maltreatment can provide an important beginning framework for future policy and practice, but...this needs to place a children's rights perspective at its centre and recognize that there are a wide range of significant social harms that cause maltreatment in children, many of which are clearly related to structural inequalities. (pp. 12-13) 
foresight and courage in implementing Essentials for Childhood and comprehensively and carefully reporting its process and effectiveness. ${ }^{3}$

\section{Looking Toward the Future}

\section{Directions for Improvement}

Essentials for Childhood is a first step toward an expansion of federal leadership in public health policy and practice with the goal of improving children's safety. Moreover, the work that is presented in this issue comprises the first phase of that endeavor. Although the re-definition of child protection to include public health organization, personnel, strategies, and goals is an important advance, the scope of the initiative thus far is still relatively modest. However, that status may be compatible with the current state of the child protection movement (cf. Metrikin-Gold 2015). In effect, Essentials for Childhood offers forums for conversation at federal, state, and local levels about needs and strategies for child protection reform.

The evaluations published in this issue lay the foundation for expansion of Essentials for Childhood in time (moving to new phases), expansion in geography (adding new state grantees), and improvement in strategies. In that context, we respectfully suggest some possible improvements in future application of the approach (see also the challenges discussed supra).

Emphasize substantive reform more than coalition building. In discussion of another effort to bring child protection organizations together (although at the national level), one of us wondered whether "we are past the time for coalition building":

The systems of response to family violence [including child maltreatment] are badly broken. The fundamental problems are not ones of weak public support as much as they are errors of design. We need intellectual rigor, moral leadership, and creative social and legal architecture, not unanimity. (Melton 2002, p. 583)

It was common in the 1980 s and 1990 s to create commissions and inter-agency councils, re-structure agencies, hold community meetings, etc. with the intention of improving coordination, developing common language, etc. in child and family services (see, e.g., Small et al. 2002). Such efforts were derived from recognition that juvenile justice, child welfare, child mental health services, special education, and youth-serving organizations (e.g., 4-H) had overlapping histories, missions, and clientele but that they often also had conflicting goals, staff with divergent professional identities, limited responsiveness to families, fragmented funding, and inefficient administration (see, e.g., Levine and Levine 1992). Moreover, the various service

\footnotetext{
${ }^{3}$ A similar evidence-driven perspective was demonstrated by Haskins et al. (2007), who are influential scholars with experience in public administration. In their 2007 book, however, Haskins et al. focused their attention exclusively on the specialty child welfare system in interaction with physical and mental health services. Hence, primary prevention altogether and therapeutic engagement by helpers outside specialty formal service systems are outside the scope of the Haskins et al. volume.
} 
systems often shared in reliance on services that were ineffective, expensive, and unduly restrictive of liberty and invasive of family privacy (Melton et al. 1998).

Although initiatives for child and family service reform sometimes persist in a strategy of simply bringing providers together, major foundations now often regard such efforts with some skepticism. Simply bringing agency leaders together neither promotes strategic reform, strengthens community engagement, nor broadens social and economic support for families with children.

The collective impact approach goes a step further by gathering organizations in multiple sectors to promulgate a common message. However, it also does not directly change community norms or enhance community resources.

Emphasize informal efforts in the various settings of everyday life for children, parents, and families, and broaden the range of organizations involved accordingly. Especially given the predominance of neglect in the epidemiology of child maltreatment, a principal challenge in child protection is to enable easy and timely "natural" availability of both economic and social support (see, e.g., McLeigh 2013; Melton 2013; Spilsbury and Korbin 2013). Formal agency programs rarely change community norms. However, Essentials for Childhood in its initial phase attended almost exclusively to health and human service agencies. Even the business sector (the exception to the rule in some participating states) focused primarily on formal structures (family-friendly business practices; i.e., for the most part, human resource policies). To build a protective community, planners must go much further to generate care for children and families in the settings of everyday life-schools, places of worship, recreation centers, housing developments, public safety agencies, etc.

Expand the public health approach to child protection to include primary care clinics and related settings (e.g., school health programs). In so doing, emphasize engagement of communities and of leaders at multiple levels. In Essentials for Childhood, CDC understandably worked with its usual clients (i.e., state public health agencies). The approach often appeared to be epidemiological (e.g., examining risk factors and protective factors). Attention needs to be given to the enlistment of community health providers in strengthening support systems for children and families. For example, group well visits may be a way of building networks for family support (see, e.g., Rushton and Kraft 2013). State agency hierarchies often have little connection to community service providers even in their own sector. They are clearly ill-suited to community building in other sectors.

\section{The Next Phase for Essentials for Childhood}

In 2018, CDC announced a Notice of Funding Opportunity for the second face of the initiative. All five original grantees received funding for 5 years. Two new grantees, both self-supported states (Utah and Kansas), will also be taking part in the initiative. As described in the article in this issue by Wasilewski et al., this next phase aims to build on the planning, goal setting, and collaboration developed in the first years of the initiative to strengthen economic supports for children and families and to change social norms that promote safe, stable, nurturing relationships and environments. 
It is our hope that the directions for improvement set forth in this commentary prove helpful in devising strategies to meet these goals. In particular, the inclusion of community leaders and representatives of community institutions (e.g., nonprofits; community groups; religious institutions; primary care clinics) will be critical to efforts aimed at increasing supports for families and changing social norms.

In writing about child protection strategies in an international context, Wessells (2015) concluded that:

... bottom-up approaches not only complement the more widely used top-down approaches but also help to unlock the prodigious creative and practical capacities of communities. Collectively, we will do a better job of protecting children if we step out of our expert role and facilitate the community-driven action and the related social transformation that supports vulnerable children. (p. 20)

Further, in an essay focused on the need to create a new comprehensive system of care for children birth-to-5, Dodge (2018) expressed the need for the combining of "a topdown approach of improving community capacity to serve families with a bottom-up approach of reaching every young child to assess child-specific needs and to connect them with targeted community resources" (p. 1118).

The research cited in this commentary provides ample support for the application of these recommendations in the context of Essentials for Childhood. The groundwork carried out in the first phase of the initiative brings with it the possibility for more than just a reframing of how we think about child maltreatment prevention. Indeed, it has the potential to redesign how government works with entities at multiple levels (e.g., neighborhoods; counties; states) to demand the safety of children and families. We should aim for nothing less.

Publisher's Note Springer Nature remains neutral with regard to jurisdictional claims in published maps and institutional affiliations.

\section{References}

Barnhart, S., \& Maguire-Jack, K. (2016). Single mothers in their communities: The mediating role of parenting stress and depression between social cohesion, social control, and child maltreatment. Children and Youth Services Review, 70, 37-45.

Barry, F. D. (1994). A neighborhood-based approach: What is it? In G. B. Melton \& F. D. Barry (Eds.), Protecting children from abuse and neglect: Foundations for a new national strategy (pp. 14-39). New York: Guilford.

Bassett, M. T. (2013). A new vision for the child abuse prevention program. New York: Doris Duke Charitable Foundation.

Belsky, J. (1980). Child maltreatment: an ecological integration. American Psychologist, 35, 320-335.

Cancian, M., Yang, M.-Y., \& Slack, K. S. (2013). The effect of additional child support income on the risk of child maltreatment. Social Service Review, 87, 417-437.

Centers for Disease Control and Prevention, National Center for Injury Prevention and Control, Division of Violence Prevention. (2013). Essentials for Childhood: Steps to create safe, stable, and nurturing relationships and environments. Atlanta: Centers for Disease Control and Prevention.

Child Trends. (2018). Child maltreatment. Retrieved from https://www.childtrends.org/indicators/childmaltreatment. Accessed 2 Nov 2018.

Coulton, C. J., Richter, F. G., Korbin, C., Crampton, D., \& Spilsbury, J. C. (2018). Understanding trends in neighborhood child maltreatment rates: a three-wave panel study 1990-2010. Child Abuse \& Neglect, 84, $170-181$. 
Dahl, T. S. (1985). Child welfare and social defence: Science state and the professions during the emergence of child welfare in Norway. Oslo: Norwegian University Press.

Dodge, K. A. (2018). Toward population impact from early childhood psychological interventions. American Psychologist, 73, 1117-1129.

Dodge, K. A., Berlin, L. J., Epstein, M., Spitz-Roth, A., O’Donnell, K., Kaufman, M., et al. (2004). The Durham family initiative. Child Welfare, 83, 109-120.

Drake, B., \& Pandey, S. (1996). Understanding the relationship between neighborhood poverty and specific types of child maltreatment. Child Abuse \& Neglect, 20, 1003-1018.

Emery, C. R., Trung, H. N., \& Wu, S. (2015). Neighborhood informal social control and child maltreatment: A comparison of protective and punitive approaches. Child Abuse \& Neglect, 41, 158-169.

Finkelhor, D., Saito, K., \& Jones, L. (2015). Updated trends in child maltreatment, 2013. Durham: University of New Hampshire, Crimes Against Children Research Center.

FrameWorks Institute. (2004). Making the public case for child abuse and neglect. Retrieved from https://www.frameworksinstitute.org. Accessed 12 Nov 2018.

FrameWorks Institute. (2009). Summary research memo: FrameWorks' analysis of frame effects on PCAA policies and implications for messaging. Retrieved from https://www.frameworksinstitute.org. Accessed 18 Nov 2018.

Freisthler, B. (2004). A spatial analysis of social disorganization, alcohol access, and rates of child maltreatment in neighborhoods. Children and Youth Services Review, 26, 803-819.

Freisthler, B., Johnson-Motoyama, M., \& Kepple, N. J. (2014). Inadequate child supervision: The role of alcohol outlet density, parent drinking behavior, and social support. Children and Youth Services Review, 43, 75-84.

Garbarino, J., \& Kostelny, K. (1992). Child maltreatment as a community problem. Child Abuse \& Neglect, $16,455-464$.

Garbarino, J., \& Sherman, D. (1980). High-risk neighborhoods and high-risk families: The human ecology of child maltreatment. Child Development, 51, 188-198.

Gelles, R. J. (2017). Out of harm's way: Creating an effective child welfare system. New York: Oxford University Press.

Haas, B. M., Berg, K. A., Schmidt-Sane, M. M., Korbin, J. E., \& Spilsbury, J. C. (2018). How might neighborhood built environment influence child maltreatment? Caregiver perceptions. Social Science \& Medicine, 214, 171-178.

Haskins, R., Wulczyn, F., \& Webb, M. B. (Eds.). (2007). Child protection: Using research to improve policy and practice. Washington, DC: Brookings Institution Press.

Huntington, C. (2014). Failure to flourish: How law undermines family relationships. New York: Oxford University Press.

Kania, J., \& Kramer, M. (2011). Collective impact. Stanford Social Innovation Review, 35-41.

Kempe, C. H. (1978). Sexual abuse, another hidden pediatric problem: The 1977 C. Anderson Aldrich Lecture. Pediatrics, 62, 382-389.

Kempe, C. H., Silverman, F. N., Steele, B. F., Droegemueller, W., \& Silver, H. K. (1962). The battered-child syndrome. JAMA, 181, 17-24.

Kim, B., \& Maguire-Jack, K. (2015). Community interaction and child maltreatment. Child Abuse \& Neglect, $41,146-157$.

Kimbrough-Melton, R. J., \& Melton, G. B. (2015). "Someone will notice, and someone will care": How to build Strong Communities for children. Child Abuse \& Neglect, 41, 67-78.

Levine, A. G., \& Levine, M. (1992). Helping children: A social history. New York: Oxford University Press.

Maguire-Jack, K., \& Font, S. A. (2017). Intersections of individual and neighborhood disadvantage: Implications for child maltreatment. Children and Youth Services Review, 72, 44-51.

Maguire-Jack, K., \& Showalter, K. (2016). The protective effect of neighborhood social cohesion in child abuse and neglect. Child Abuse \& Neglect, 52, 29-37.

Maguire-Jack, K., \& Wang, X. (2016). Pathways from neighborhood to neglect: The mediating effects of social support and parenting stress. Children and Youth Services Review, 66, 28-34.

McDonell, J. R., \& Skosireva, A. (2009). Neighborhood characteristics, child injuries, and child maltreatment. Child Indicators Research, 2, 133-153.

McDonell, J. R., Ben-Arieh, A., \& Melton, G. B. (2015). Strong communities for children: Results of a multiyear community-based initiative to protect children from harm. Child Abuse \& Neglect, 41, 79-96.

McLeigh, J. D. (2013). How to form alliances with families and communities. Child Abuse \& Neglect, 37(Supp), 17-28.

McLeigh, J. D., \& Melton, G. B. (2015). Children's safety in community context [editorial]. Child Abuse \& Neglect, 41, 1-2. 
McLeigh, J. D., McDonell, J. R., \& Lavenda, O. (2018). Neighborhood poverty and child abuse and neglect: the mediating role of social cohesion. Children and Youth Services Review, 93, 154-160.

Melton, G. B. (1992). It's time for neighborhood research and action. Child Abuse \& Neglect, 16, 909-913.

Melton, G. B. (2002). Chronic neglect of family violence: more than a decade of reports to guide U.S. policy. Child Abuse and Neglect, 26, 569-586.

Melton, G. B. (2013). "Programs" aren't enough. Child Abuse \& Neglect, 37(Supp), 1-7.

Melton, G. B., \& Barry, F. D. (Eds.). (1994). Protecting children from abuse and neglect: Foundations for a new national strategy. New York: Guilford.

Melton, G. B., Lyons, P. M., Jr., \& Spaulding, W. J. (1998). No place to go: The civil commitment of minors. Lincoln: University of Nebraska Press.

Melton, G. B., Thompson, R. A., \& Small, M. A. (Eds.). (2002). Toward a child-centered, neighborhoodbased child protection system. Westport: Praeger.

Metrikin-Gold, B. D. (2015). Personal reflections about the work of the U.S. Advisory Board on Child Abuse and Neglect. Child Abuse and Neglect, 41, 3-18.

Molnar, B. E., Goerge, R. M., Gilsanz, P., Hill, A., Subramanian, S. V., Holtone, J. K., . . Beardslee, W. R. (2016). Neighborhood-level social processes and substantiated cases of child maltreatment. Child Abuse \& Neglect, 51, 41-53.

Myers, J. E. B. (2008). A short history of child protection in America. Family Law Quarterly, 42, 449-463.

Nadan, Y., Spilsbury, J. C., \& Korbin, J. E. (2015). Culture and context in understanding child maltreatment: Contributions of intersectionality and child maltreatment. Child Abuse \& Neglect, 41, 40-48.

National Commission on Children. (1991). Beyond rhetoric: A new American agenda for children and families. Washington, DC: U.S. Government Printing Office.

Nelson, B. J. (1984). Making an issue of child abuse: Political agenda setting for social problems. Chicago: University of Chicago Press.

Parton, N. (1985). The politics of child abuse. Basingstoke: Macmillan.

Parton, N. (1991). Governing the family: Child care, child protection, and the state. Basingstoke: Macmillan.

Parton, N. (2006). Safeguarding childhood: Early intervention and surveillance in a late modern society. Basingstoke: Palgrave Macmillan.

Parton, N. (2014). The politics of child protection: Contemporary developments and future directions. Basingstoke: Palgrave Macmillan.

Pelton, L. H. (2015). The continuing role of material factors in child maltreatment and placement. Child Abuse \& Neglect, 41, 30-39.

Rushton, F. E., \& Kraft, C. (2013). Family support in the family-centered medical home: an opportunity for preventing toxic stress and its impact in young children. Child Abuse \& Neglect, 37(Supp), 41-50.

Schorr, L. (1988). Within our reach: Breaking the cycle of disadvantage. New York: Doubleday.

Slack, K. S., Font, S., Maguire-Jack, K., \& Berger, L. M. (2017). Predicting child protective services (CPS) involvement among low-income U.S. families with young children receiving nutritional assistance. International Journal of Environmental Research and Public Health, 14, 1197-1208.

Small, M. A., Melton, G. B., Olson, K. A., \& Tomkins, A. J. (2002). Creating caring communities: The need for structural change. In G. B. Melton, R. A. Thompson, \& M. A. Small (Eds.), Toward a child-centered, neighborhood-based child protection system (pp. 263-279). Westport: Praeger.

Spilsbury, J. C., \& Korbin, J. E. (2013). Social supports and informal social support in protecting children from abuse and neglect. Child Abuse \& Neglect, 37(Supp), 8-16.

Thompson, R. A. (1995). Preventing child maltreatment through social support: A critical analysis. Thousand Oaks: Sage.

Thompson, R. A. (2015). Social support and child protection: Lessons learned and learning. Child Abuse \& Neglect, 41, 19-29.

Turner, R. J., \& Avison, W. R. (1985). Assessing risk factors for problem parenting: The significance of social support. Journal of Marriage and Family, 47, 881-892.

U.S. Advisory Board on Child Abuse and Neglect. (1990). Child abuse and neglect: Critical first steps in response to a national emergency. Washington, DC: U.S. Government Printing Office.

U.S. Advisory Board on Child Abuse and Neglect. (1993). Neighbors helping neighbors: A new national strategy for the protection of children. Washington, DC: U.S. Government Printing Office.

U.S. Department of Health and Human Services. (2018). Child maltreatment. Washington, DC: Author.

Warren, E. J., \& Font, S. A. (2015). Housing insecurity, maternal stress, and child maltreatment: an application of the family stress model. Social Service Review, 89, 9-39.

Weissbourd, B., \& Grimm, C. (1981). Family focus: Supporting families in the community. Children Today, $10(2), 6-11$. 
Wessells, M. G. (2015). Bottom-up approaches to strengthening child protection systems: placing children, families, and communities at the center. Child Abuse \& Neglect, 43, 8-21.

Yang, M.-Y. (2015). The effect of material hardship on child protective service involvement. Child Abuse \& Neglect, 41, 113-125.

Yang, M.-Y., \& Maguire-Jack, K. (2016). Predictors of basic needs and supervisory neglect: evidence from the Illinois families study. Children and Youth Services Review, 67, 20-26.

Zolotor, A. J., \& Runyan, D. (2006). Social capital, family violence, and neglect. Pediatrics, 117, e1124-e1131. 